\title{
Contrast enhancement features of tubular adenoma, MRI and contrast enhanced mammography pictorial report
}

\author{
Sara Faye Borenstein, Tal Friehmann, Yael Rapson, Shlomit Tamir, Eli Atar, Ahuva Grubstein* \\ Department of Radiology, Rabin Medical Center - Beilinson Hospital, Petach Tikva, Israel
}

Received: February 14, 2020

DOI: $10.5430 /$ dcc.v6n2p24
Accepted: May 8, 2020

Online Published: May 13, 2020

URL: https://doi.org/10.5430/dcc.v6n2p24

\begin{abstract}
Introduction: Tubular adenomas are rare benign epithelial neoplasms of the breast resembling fibroadenomas on both imaging and pathology. We aimed at characterizing and differentiating these lesions on contrast enhanced mammography and MRI.

Material and methods: Out of all percutaneous breast biopsies performed at the Rabin medical center between the years 2010-2019, five cases which also had contrast-based imaging including contrast enhanced mammography and MRI were retrieved. Morphology and enhancement patterns of the lesions were analyzed by two dedicated breast radiologists.

Results: The contrast imaging characteristics of all lesions were enhancing masses measuring 4-17 mm. The shape of the lesions was oval, borders well circumscribed, on both CEM and MRI. CEM revealed marked homogenous enhancement. MRI enhancement patterns of the small tumors showed homogenous enhancement, whereas the larger mass showed a more heterogeneous enhancement. Kinetic curves on MRI were of rapid marked enhancement.

Conclusion: Tubular adenomas diverge pathologically from known enhancement patterns of fibroadenomas.
\end{abstract}

Key Words: Tubular adenoma, Contrast mammography, MRI, Breast

\section{INTRODUCTION}

Tubular adenomas are rare benign epithelial neoplasms of the breast, accounting for $0.13 \%-1.7 \%$ of benign breast lesions. ${ }^{[1,2]}$ They are often found in young women and mostly appear as circumscribed masses. Microscopically, they contain compactly tubular structures. Despite a relation to fibroadenomas, tubular adenomas differ by containing scant connective tissue and the epithelial component consists of acinar units rather than large ducts. ${ }^{[3]}$ Contrast Enhanced Mammography (CEM) and Magnetic Resonance Imaging (MRI) are used in common practice world- wide to further evaluate breast lesions suspicious of malignancy, particularly in dense breast tissue. ${ }^{[4-6]}$

The purpose of this study is to characterize and differentiate tubular adenomas from fibroadenomas, utilizing contrast enhanced breast imaging - Contrast Enhanced Mammography (CEM) and Magnetic Resonance Imaging (MRI).

\section{Material AND Methods}

Out of all percutaneous breast biopsies performed at the Rabin medical center between the years 2010-2019, 19 cases of tubular adenoma were found on pathology. Extracting only cases which also had contrast-based imaging, five cases for analysis remained. This study was approved by our institu-

\footnotetext{
*Correspondence: Ahuva Grubstein; Email: Ahuvag@clalit.org.il; Address: Department of Radiology, Rabin Medical Center - Beilinson Hospital, Petach Tikva 4941492, affiliated with Sackler Faculty of Medicine, Tel Aviv University, Tel Aviv 6997801, Israel.
} 
tional ethics committee.

\subsection{CEM technique}

All CEM images were performed at our medical center by using a digital mammography unit (Selenia Dimensions, Hologic, Bedford, MA, USA). $1.5 \mathrm{ml}$ per kilogram of body weight of Iopromide was injected intravenously to each individual (Ultravist 300, Bayer, California) at an injection rate of $3 \mathrm{ml} / \mathrm{sec}$. Approximately 2.5 minutes after injection, the patient was positioned to acquire the first mammographic image. Within 6 minutes of injection, all four images (craniocaudal and mediolateral oblique images of each breast) were taken. For each view, a low-energy exposure (28-33 $\mathrm{kVp}$ ) and a high-energy exposure (45-49 kVp) was obtained. Areas of contrast enhancement were highlighted using a recombination algorithm which subtracted unenhanced breast tissue. ${ }^{[7]}$

\subsection{MRI technique}

Breast MRI exams were performed with either a 3T or $1.5 \mathrm{~T}$ magnet (3T Ingenia and 1.5T Achieva, Philips Medical Systems, Best, Netherlands), using a dedicated 16-channel breast coil. Our protocol sequences included: 1) axial T2w turbo spin-echo (TSE) TE $120 \mathrm{msec}$, in-plane resolution $1 \mathrm{~mm}$, slice width $3 \mathrm{~mm}$ with no gap. 2) axial T2w TSE, SPAIR fat suppression. 3) axial dynamic using 2D for the $3 \mathrm{~T}$ or 3D $\mathrm{T} 1$ for the $1.5 \mathrm{~T}$ Vista sequence, TE $70 \mathrm{msec}$ for the $3 \mathrm{~T}$ and TR/TE 2,000/280 msec for the 1.5T. Six dynamics with approximately $64 \mathrm{sec}$ per dynamic for both field strengths with SPAIR fat suppression. 3T/1.5T: flip angle 12/10 degrees, TR/TE 6.3/3.0 msec / 6.6/3.2 msec, in-plane resolution $0.8 \mathrm{~mm} / 1.2 \mathrm{~mm} .^{[7,8]}$

\subsection{Image interpretation}

CEM Images were interpreted on a workstation equipped with 5-megapixel monitors (SecureView Dx, Hologic). Both CEM and MRI studies were assessed qualitatively according to the criteria of the Breast Imaging Reporting and Data System (BI-RADS) by one of two fellowship-trained radiologists (A.G, Y.R) specializing in breast imaging (14 and 8 years of experience in breast radiology, respectively).

\section{RESULTS}

Five patients with a biopsy proven tubular adenoma, who underwent CEM and/or MRI studies, were reviewed. Patients age, indication for the contrast study and lesion characteristics are summarized in Table 1 . The age range was 22-68 years, with a mean age of 49 years. Three of the patients were postmenopausal. In four out of five patients, the lesion was detected and biopsied under US guidance. One patient underwent CEM for the evaluation of mammographic architectural distortion, revealing additional contralateral focus of enhancement which was later biopsied under MRI.

The contrast imaging characteristics of all lesions were enhancing masses measuring 4-17 $\mathrm{mm}$. The shape of the lesions was oval, borders well circumscribed, on both CEM and MRI. CEM revealed marked homogenous enhancement (see Figure 1). Neither suspicious microcalcifications nor typical coarse "popcorn like" macrocalcifications were noted on the low energy mammogram images. MRI enhancement patterns of the small tumors showed homogenous enhancement, whereas the larger mass (case 5) showed a more heterogeneous enhancement. Kinetic curves on MRI showed in all cases a rapid marked enhancement (see Figure 2).

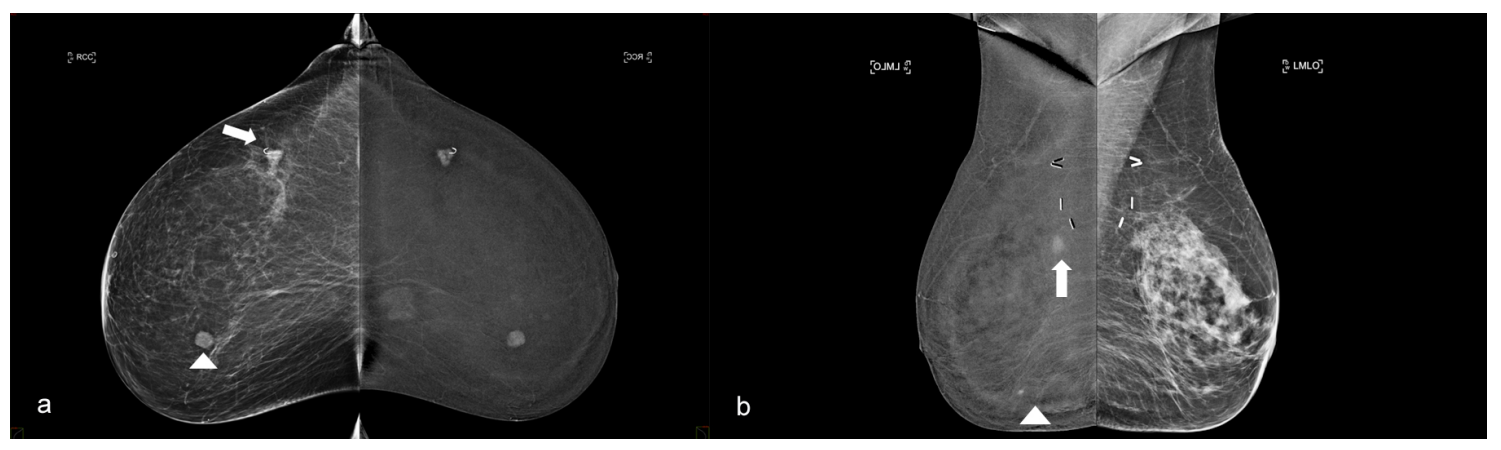

Figure 1. CEM

a. A 68-year-old, with recently diagnosed invasive ductal carcinoma in the upper-outer quadrant of her right breast. CEM was performed for the evaluation of extent of disease. The RCC image shown here, with a mirrored display of the same position CEM, shows the index tumor, marked with a clip (arrow) in the lateral half of the breast. The arrow head marks an additional mass in the medial half of the breast- an oval well circumscribed mass with homogenous enhancement. The medial mass was biopsied under ultrasound guidance and found to be a tubular adenoma. $b$. A 65-year-old female who underwent CEM for the evaluation of architectural distortion, near a prior lumpectomy scar, in the upper quadrants of the left breast. Two masses were noted on the CEM. The larger one in the upper quadrants (white arrow) was biopsied under ultrasound guidance and was found to be fat necrosis. In addition, a lower oval focus was detected, displaying homogenous enhancement for which MRI guided biopsy was performed revealing tiny tubular adenoma (arrow head). 

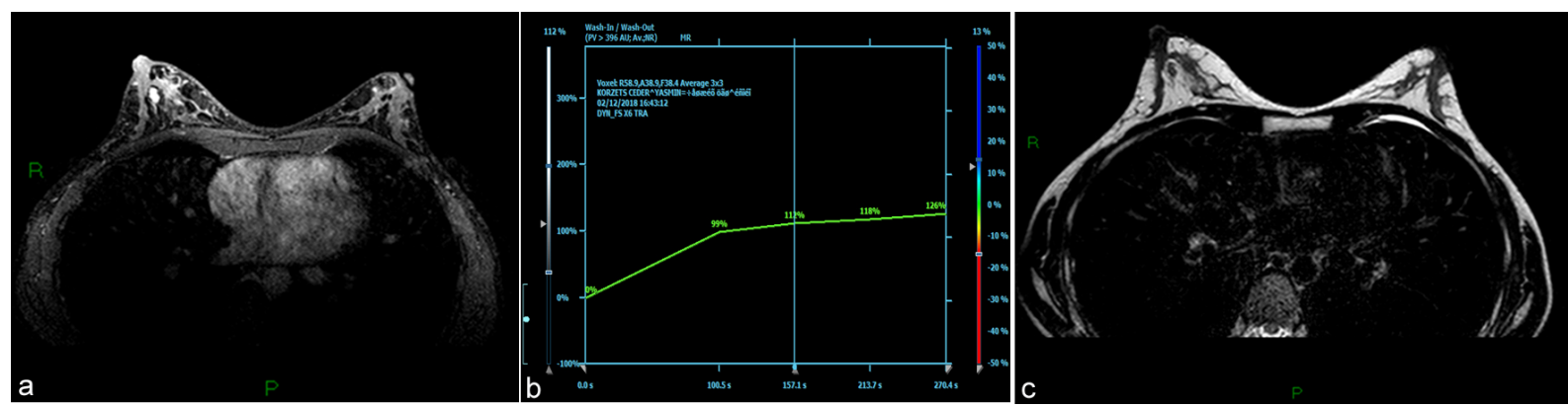

Figure 2. MRI

a. A 38-year-old, BRCA carrier, underwent routine MRI screening. Post contrast 3D T1 MRI image: in the right breast, centrally behind the nipple, an oval mass with circumscribed margins, and homogenous enhancement, is shown. The mass was new in comparison with previous MRIs, therefor an ultrasound guided biopsy was performed revealing a tubular adenoma. $b$. Kinetic curves demonstrating initial fast enhancement followed by a slow rise. $c$. T2 waited images demonstrating intermediate signal.

Table 1. Patient and lesion characteristics

\begin{tabular}{|c|c|c|c|c|c|c|c|c|c|c|}
\hline \multirow{2}{*}{$\begin{array}{l}\text { Patient } \\
\text { number }\end{array}$} & \multirow[b]{2}{*}{ Age } & \multirow{2}{*}{$\begin{array}{l}\text { Contrast study } \\
\text { indication }\end{array}$} & \multirow{2}{*}{$\begin{array}{l}\text { Contrast } \\
\text { imaging } \\
\text { modality }\end{array}$} & \multirow{2}{*}{$\begin{array}{l}\text { Size } \\
\text { mm }\end{array}$} & \multirow{2}{*}{$\begin{array}{l}\text { Mode of } \\
\text { diagnosis/ } \\
\text { biopsy }\end{array}$} & \multirow[b]{2}{*}{ CEM } & \multicolumn{3}{|c|}{ MRI } & \multirow[b]{2}{*}{ Follow up } \\
\hline & & & & & & & T2 & $\begin{array}{l}\text { T2 fat } \\
\text { suppress }\end{array}$ & $\begin{array}{l}\text { T1 } \\
\text { dynamic }\end{array}$ & \\
\hline 1 & 65 & $\begin{array}{l}\text { Breast cancer } \\
\text { extent }\end{array}$ & $\begin{array}{l}\text { CEM and } \\
\text { MRI }\end{array}$ & 4 & MR & $\begin{array}{l}\text { Enhancing } \\
\text { focus }\end{array}$ & \multicolumn{3}{|c|}{ Enhancing focus, rapid persistent } & \\
\hline 2 & 68 & $\begin{array}{l}\text { Mammographic } \\
\text { finding work up }\end{array}$ & CEM & 14 & $\begin{array}{l}\text { US- } \\
\text { isoechoic } \\
\text { oval mass }\end{array}$ & $\begin{array}{l}\text { Enhancing } \\
\text { oval mass }\end{array}$ & & & & $\begin{array}{l}\text { Stable since } \\
2011\end{array}$ \\
\hline 3 & 39 & $\begin{array}{l}\text { High risk } \\
\text { screening }\end{array}$ & MRI & 10 & US & & $\begin{array}{l}\text { Enh } \\
\text { sign }\end{array}$ & $\begin{array}{l}\text { acing oval m } \\
\text {, rapid wash }\end{array}$ & $\begin{array}{l}\text { nternal fat } \\
\text { ad plateau. }\end{array}$ & Surgical excision \\
\hline 4 & 58 & $\begin{array}{l}\text { High risk } \\
\text { screening }\end{array}$ & MRI & 7 & US & & $\begin{array}{l}\text { Enh } \\
\text { in al }\end{array}$ & $\begin{array}{l}\text { ing oval m } \\
\text { plateau. }\end{array}$ & apid wash & $\begin{array}{l}1 \text { year with MRI, } \\
\text { clip in place }\end{array}$ \\
\hline 5 & 22 & $\begin{array}{l}\text { US finding } \\
\text { work up }\end{array}$ & MRI & 17 & US & & $\begin{array}{l}\text { Het } \\
\text { mas }\end{array}$ & $\begin{array}{l}\text { ogeneous en } \\
\text { rapid wash }\end{array}$ & $\begin{array}{l}\text { ing oval } \\
\text { d plateau. }\end{array}$ & $\begin{array}{l}\text { Unchanged for } 3 \\
\text { years, MRI }\end{array}$ \\
\hline
\end{tabular}

\section{DISCUSSION}

Tubular adenomas of the breast are rare benign epithelial lesions, most found in young women, but rarely may occur in male patients. It is tempting to compare a tubular adenoma to a fibroadenoma, due to their lesion morphology resemblance on both imaging and pathology but these are separate entities due to their distinct histological characteristics. Tubular adenomas, unlike fibroadenomas, are composed of packed tubular epithelia with little interstitial stroma giving it a homogenous appearance. On the other hand, fibroadenomas are biphasic lesions containing more of a balance of the two components: adenoma and a larger interstitial stroma. ${ }^{[9,10]}$ That being said, on various imaging modalities with no contrast used, the two entities show high resemblance giving rise to the difficulty in distinguishing the two. On mammography, tubular adenomas typically do not show calcifications, similar to noncalcified fibroadenomas. In older patients, coarse calcifications may be noted in both cases as a result of degeneration of the fibroadenoma. On US, tubular adenomas resemble fibroadenomas, as they both may appear as non-calcified well circumscribed hypoechoic lesions. Their relatively homogeneous internal texture results in posterior enhancement. ${ }^{[11,12]}$

Tubular adenomas pose little to no risk of malignant transformation, despite the terminological resemblance to tubular carcinoma. $^{[12]}$

In this case series, tubular adenomas were found to have characteristic morphology and enhancement patterns on CEM and MRI. The lesions were found to be well defined oval masses with majority showing homogenous enhancement, rapid on the kinetic curves. The enhancement characteristics of tubular adenoma lesions are due to the tubular epithelial component, which is homogenous in structure. Fibroadenomas on the other hand, may exhibite low signal intensity internal septations, on T1 weighted, post-contrast non-subtracted images or on T2 weighted images. Internal septations are very specific for fibroadenoma. Unfortunately breast MRI studies with limited spatial resolution these internal septations are often not seen. ${ }^{[13]}$ Of notice, the classic "popcorn 
like" calcifications pathognomonic for fibroadenoma, were absent on the low energy 2D mammograms on the CEM in our cases.

In conclusion, tubular adenomas of the breast which share resemblance on non-contrasted imaging with fibroadenomas may have different characteristic appearances on contrast enhanced breast studies, corresponding with the histological differences these two entities hold. Clinicians may find this of aid, enabling better radiology-pathology correlation.

\section{CONFlicts OF InTEREST Disclosure}

The authors declare they have no conflicts of interest.

\section{REFERENCES}

[1] Lakhani SR, Ellis IO, Schnitt SJ, et al. WHO Classification of Tumours of the Breast. 4th ed. Lyon, France: IARC; 2012.

[2] Tavassoli FA, Devilee P. Pathology and genetics of tumors of the breast and female genital organs. IARC; 2003.

[3] Mary SS, Nilima D, Rex B, et al. Tubular Adenomas of the Breast Imaging Findings with Histologic Correlation. American Journal of Roentgenology. 2000; 174: 757-761. PMid:10701621. https: //doi.org/10.2214/ajr.174.3.1740757

[4] Sorin V, Yagil Y, Yosepovich A, et al. Contrast-Enhanced Spectral Mammography in Women With Intermediate Breast Cancer Risk and Dense Breasts. AJR Am J Roentgenol. 2018; 211(5): W267-W274. PMid:30240292. https://doi.org/10.2214/AJR.17.19355

[5] Dromain C, Balleyguier C, Adler G, et al. Contrast-enhanced digital mammography. Eur J Radiol. 2009; 69: 34-42. PMid:18790584. https://doi.org/10.1016/j.ejrad.2008.07.035

[6] Lobbes MB, Smidt ML, Houwers J, et al. Contrast-enhanced mammography: techniques, current results, and potential indications. Clin Radiol. 2013; 68: 935-944. PMid:23790689. https://doi.org/ $10.1016 /$ j.crad.2013.04.009

[7] Ahuva G, Yael R, Oshra BZ, et al. Comparison of background parenchymal enhancement and fibroglandular density at breast magnetic resonance imaging between BRCA gene mutation carriers and non-carriers. Clinical Imaging. 2018; 51: 347-351. PMid:29982132. https://doi.org/10.1016/j.clinimag. 2018.06.010

[8] Ahuva G, Yael R, Sara M, et al. Invasive Lobular Carcinoma of the Breast: Appearance on Digital Breast Tomosynthesis. Breast Care. 2016; 11(5): 359-362. PMid:27920631. https://doi .org/10.1 $159 / 000450868$

[9] Yousif S, Abber F, Noof A. Breast tubular adenoma. International Surgery Journal. 2019; 6(8): 2985-2987. https ://doi .org/10.1 8203/2349-2902. isj20193349

[10] Nikolaos SS, Georgios G, Gregorios K, et al. Tubular Adenoma of the Breast: A Rare Presentation and Review of the Literature. J Clin Med Res. 2012; 4(1): 64-67.

[11] Irshad A, Ackerman SJ, Pope TL, et al. Rare Breast Lesions: Correlation of Imaging and Histologic Features with WHO Classification. 2008; 28(5): 1399-414. PMid:18794315. https ://doi.org/10.1 $148 / \mathrm{rg} .285075743$

[12] Domoto H, Tsuda H, Miyakawa K, et al. Invasive ductal carcinoma associated with tubular adenoma of the breast. Pathol Int. 2002; 52(3): 244-248. PMid:11972869. https://doi.org/10.1046/j.1440 $-1827.2002 .01338 . x$

[13] Kuhl CK. MRI of breast tumors. Eur. Radiol. 2000; 10: 46-58. PMid:10663717. https://doi.org/10.1007/s003300050006 